\title{
Effects of Lymphovascular Invasion on Overall and Cancer-specific Survival after Radical Cystectomy in Patients with Bladder Cancer
}

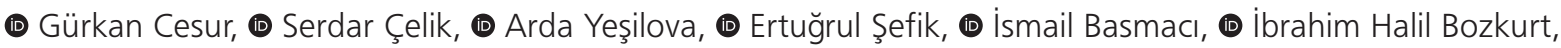 \\ (D) Serkan Yarımoğlu, (1) Bülent Günlüsoy, (D) Tansu Değirmenci
}

University of Health Sciences Turkey, Izmir Bozyaka Training and Research Hospital, Clinic of Urology, Izmir, Turkey

\begin{abstract}
Objective: We aimed to investigate the effects of lymphovascular invasion (LVI) on survival rate, as well as the relationship of this parameter with lymph node (LN) involvement and other prognostic factors, in patients undergoing radical cystectomy (RC) for bladder cancer.

Materials and Methods: Patients who underwent RC in our clinic for muscle invasive bladder cancer (MIBC) or high-risk non-muscle invasive bladder cancer (NMIBC) between 2006 and 2019 were retrospectively reviewed. Patients were divided into four groups: LVI (-) and LN (-) patients were in group 1, LVI (+) and LN $(-)$ patients were in group 2, LVI (-) and LN (+) patients were in group 3, and LVI (+) and LN (+) patients were in group 4. All data were compared among the groups. Results: A total of 177 patients with a mean age of 64.4 years and mean follow-up time of 30.2 months were evaluated in this study. The mean overall survival (OS) and cancer-specific survival (CSS) of the patients were $56.6 \pm 4.2$ and $68.9 \pm 4.5$ months, respectively. When factors affecting survival rates were analyzed, LN positivity was not a significant factor influencing the OS $(p=0.570)$ and CSS $(p=0.533)$ of the patients. However, LVI $[p=0.002$, hazard ratio $(H R)=0.402]$ and surgical margin (SM) positivity ( $p=0.001, H R=0.321)$ were significant factors influencing OS. SM positivity $(p=0.003, H R=0.314), L V I(p=0.011, H R=0.416)$, and adjuvant chemotherapy $(\mathrm{ACT})(\mathrm{p}=0.009, \mathrm{HR}=0.460)$ were also found to be independent factors affecting CSS. ACT was higher in group 3 than in other groups, and overall and cancer-specific mortality rates were lower in group 1 than in other groups. OS and CSS in group $2(15.3 \pm 2.9$ and $21.2 \pm 4.6$ months, respectively) and group 4 (21.5 \pm 7.2 and $24.5 \pm 8.1$ months, respectively) were lower than those in other groups $(p<0.001)$.

Conclusion: SM positivity and LVI are independent factors affecting OS and CSS. ACT, especially in group 3, could increase CSS. OS and CSS were lower in patients with LVI than in those without.
\end{abstract}

Keywords: Bladder cancer, lymphovascular invasion, lymph node involvement, overall survival, cancer-specific survival

\section{Introduction}

Bladder cancer is one of the most common malignancies of the urinary system, and its prevalence is high in developing countries (1). The annual mortality rate of this type of cancer is $1-5 / 100000$ for males and $0.5-1.5 / 100000$ for females (2). Approximately, $98 \%$ of all bladder cancers originate from the epithelial layer, and $80-90 \%$ of these carcinomas are urothelial in nature (3). At the time of diagnosis, approximately $75 \%$ of patients are found to have non-muscle invasive bladder cancer (NMIBC), while $25 \%$ have muscle invasive bladder cancer (MIBC) $(4,5)$. Radical cystectomy (RC) with extended lymph node ( $L N)$ dissection and urinary diversion is the gold standard treatment for patients with MIBC (6). Besides this treatment, adjuvant chemotherapy (ACT) is required for patients with poor prognosis. Morbidity and mortality can be observed in approximately $50 \%$ of patients after RC (7). The prognostic criteria of bladder cancer include LN metastasis, surgical margin (SM) positivity, presence of carcinoma in situ (CIS), lymphovascular invasion (LVI), and ineligibility to receive ACT $(8,9,10,11,12)$. LVI is defined as the presence of tumor cells in lymphatic vessels and the vascular wall, which could increase the frequency of LN metastasis. Intravasation of cancer cells to the circulation via LVI and the development of micrometastases is one of the most important processes for metastatic disease (13). Previous research showed that LVI is a poor prognostic marker for testicular cancer and penile cancer (14). LVI in RC specimens is also known to be an independent prognostic factor for LN involvement, recurrence, and survival in patients with MIBC (15). Earlier studies demonstrated that LVI has negative effects on survival, especially among LN (-) patients (16). Therefore, in the present study, we aimed to investigate the effects of LVI and

Cite this article as: Cesur G, Çelik S, Yeşilova A, Şefik E, Basmacı I, Bozkurt IH, Yarımoğlu S, Günlüsoy B. Değirmenci T. Effects of Lymphovascular Invasion on Overall and Cancer-specific Survival after Radical Cystectomy in Patients with Bladder Cancer Bull Urooncol 2021;20(3):174-178

Address for Correspondence: Gürkan Cesur, University of Health Sciences Turkey, İzmir Bozyaka Training and Research Hospital, Clinic of Urology, İmir, Turkey E-mail: gurkancesur1992@hotmail.com ORCID-ID: orcid.org/0000-0001-9089-3452 Received: 10.06.2020 Accepted: 14.06.2020 
LN involvement on the overall survival (OS) and cancer-specific survival (CSS) of patients groups divided according to LVI and LN status after RC; the relationships of LVI with other prognostic factors are also evaluated.

\section{Materials and Methods}

Patients who underwent RS for MIBC or high-risk NMIBC between 2006 and 2019 in our clinic were retrospectively evaluated. Patients who had complete data and followed up in our clinic were included in the study. Patients diagnosed with other types of bladder cancer except urothelial carcinoma, those who received neoadjuvant chemotherapy, and those who had missing follow-up data were excluded from the study. The patients' characteristics and preoperative, perioperative, and postoperative data were reviewed. Clinical (i.e., age, gender, and preoperative hydronephrosis), preoperative pathological (i.e., preoperative T-stage and grade and presence of CIS), postoperative pathology (i.e., RC T-stage, number of LNs removed, $L N$ involvement, and $L V I)$, and oncological (i.e., upstaging, ACT, overall mortality, OS, cancer-specific mortality, and CSS) data were evaluated. Patients were divided into four groups according to their LVI and LN status described their final RC pathology reports. LVI (-) and LN (-) patients were categorized into group 1, LVI (+) and LN (-) patients were categorized into group 2, LVI (-) and LN (+) patients were categorized into group 3 , and LVI (+) and LN (+) patients were categorized into group 4. All data were compared among the groups.

\section{Statistical Analysis}

Data were analyzed using Statistical Package for Social Sciences version 22.0 (SPSS, Chicago, IL, USA). The Kruskal-Wallis and chisquared tests were used for univariate analysis. For multivariate analysis, Cox regression analysis was used to investigate the factors affecting OS and CSS. Inter-group survival analysis was evaluated by Kaplan-Meier survival analysis. Statistical significance was accepted as $\mathrm{p}<0.05$.

\section{Results}

A total of 177 patients with a mean age and follow-up time of 64.4 \pm 9.4 years (range, 32-83 years) and 30.2 \pm 31.1 months (range, 1-116 months) were evaluated in this study. The mean OS and CSS of the patients were 56.6 \pm 4.2 and $68.9 \pm 4.5$ months, respectively. When factors affecting survival rates were analyzed, LN positivity was not a significant predictive factor for OS $(p=0.570)$ and CSS $(p=0.533)$. However, LVI $[p=0.002$, hazard ratio $(H R)=0.402]$ and SM positivity $(p=0.001, H R=0.321)$ were significant predictive factors for OS. SM positivity $(p=0.003$, $H R=0.314)$, LVI $(p=0.011, H R=0.416)$, and ACT $(p=0.009$, $\mathrm{HR}=0.460$ ) were also found to be independent predictive factors for CSS.

When we analyzed the groups based on LN and LVI status, 121 patients were categorized into group 1, 15 were categorized into group 2, 24 were categorized into group 3, and 17 were categorized into group 4. The distribution of pathological and clinical features and comparative results of the groups are given in Table 1. The demographic and preoperative pathological data were statistically similar between the groups. However, T-stage in the RC final pathology, SM positivity, and upstaging were significantly lower in group 1 and higher in group 4 than in other groups. The numbers of dissected LNs were similar between the groups. The ACT rate was higher in group 3 than in other groups, and overall and cancer-specific mortality rates were generally lower in group 1 than in other groups. The OS and CSS of group 2 (15.3 \pm 2.9 and $21.2 \pm 4.6$ months, respectively) and group 4 (21.5 \pm 7.2 and $24.5 \pm 8.1$ months, respectively) were found to be lower compared with those of other groups $(p<0.001)$. The OS and CSS plots are given in Figures 1 and 2 .

\section{Discussion}

MIBC often leads to high mortality despite RC and additional adjuvant or neoadjuvant treatments. Several prognostic factors have been found to be related to this high level of mortality. Thus, in the present work, we aimed to focus on one of these prognostic factors.

LVI has been shown in previous studies to be a risk factor for LN metastasis, recurrence, and poor OS (13). In our study, when we examined the effect of LVI on OS and CSS, we found that it was an independent factor for poor prognosis $(p=0.002, H R=0.402$ and $\mathrm{p}=0.011$, $\mathrm{HR}=0.416$, respectively). OS and CSS times were found to be lower in group 2 (15.3 and 21.2 months, respectively) and group 4 (21.5 and 24.5 months, respectively) than in group 1 (66 and 77.8 months, respectively) and group 3 (43.9 and 54.8 months, respectively) $(p<0.001)$. This finding reveals that $\mathrm{LVI}$ is an independent prognostic factor that is as equally effective as LN positivity for predicting survival. Previous research reported that LVI is an independent predictor for LN metastasis $(17,18)$. An earlier meta-analysis also showed that LVI occurred in $64.4 \%$ of LN (+) patients and $36 \%$ of LN (-) patients $(19,20)$. In the current study, LVI was found in $41.5 \%$ (group 4) of LN (+) patients (groups 3 and 4) and in 11\% (group 2) of LN (-) patients (groups 1 and 2). LN positivity is generally acknowledged to have a negative effect on survival rates. However, in the present study, LN positivity did not have a statistically significant effect on OS and CSS ( $p=0.570$ and $p=0.533$, respectively). When we examined the factors responsible for this finding, we found that the rate of patients receiving ACT in group 3 was as high as $54.2 \%$. The rates of patients receiving ACT were not distributed similarly among the groups. Moreover, group 4 revealed the highest upstaging rates and RC T-stages. As an important limitation of this study, the low number of patients in the groups may have contributed to this finding.

Another prognostic factor affecting OS in our study was SM positivity $(p=0.001, H R=0.321)$. The independent prognostic factors affecting CSS were SM positivity $(p=0.003, H R=0.314)$ and ACT $(p=0.009, H R=0.460)$. OS and CSS were higher in group 3 than in group 4 . Although LVI positivity in group 4 may contribute to this finding, the higher rate of ACT in group 3 than in group 4 may also explain this result (54.2\% vs $35.3 \%)$. When we planned this study according to our hypothesis, we aimed to investigate how LVI affects OS and CSS, especially among LN (-) patients. However, our findings appeared to be more important than our hypothesis (21). Similar to our hypothesis, Lotan et al. (22) showed the prognostic significance of LVI in LN (-) patients 


\begin{tabular}{|c|c|c|c|c|c|c|}
\hline & & $\begin{array}{l}\text { Group } 1 \\
\text { LVI }(-) \text { and LN (-) } \\
(n=121)\end{array}$ & $\begin{array}{l}\text { Group } 2 \\
\text { LVI (+) and LN (-) } \\
(n=15)\end{array}$ & $\begin{array}{l}\text { Group } 3 \\
\text { LVI }(-) \text { and LN (+) } \\
(n=24)\end{array}$ & $\begin{array}{l}\text { Group } 4 \\
\text { LVI }(+) \text { and LN (+) } \\
(n=17)\end{array}$ & $\mathbf{p}$ \\
\hline \multicolumn{2}{|l|}{ Age } & $64.2 \pm 9.7(32-83)$ & $66.3 \pm 9.1(54-80)$ & $64.9 \pm 8.3(47-79)$ & $63.5 \pm 9.3(46-79)$ & 0.903 \\
\hline \multirow{2}{*}{ Gender } & Male & $111(91.7)$ & $13(86.7)$ & $22(91.7)$ & $16(94.1)$ & \multirow{2}{*}{0.894} \\
\hline & Female & $10(8.3)$ & $2(13.3)$ & $2(8.3)$ & $1(5.9)$ & \\
\hline \multicolumn{2}{|c|}{ Preoperative hydronephrosis } & 37 (30.6) & $5(33.3)$ & $14(58.3)$ & $5(29.4)$ & 0.082 \\
\hline \multirow{3}{*}{ Preoperative T-stage } & $\leq \mathrm{T} 1$ & $15(12.7)$ & $2(13.3)$ & $1(4.3)$ & $0(0)$ & \multirow{3}{*}{0.06} \\
\hline & $\mathrm{T} 2$ & $101(85.6)$ & $11(73.3)$ & $22(95.7)$ & $17(100)$ & \\
\hline & T3 & $2(1.7)$ & $2(13.3)$ & $0(0)$ & $0(0)$ & \\
\hline \multirow{3}{*}{ Preoperative grade } & G1 & $3(2.5)$ & $1(6.7)$ & $0(0)$ & $0(0)$ & \multirow{3}{*}{0.577} \\
\hline & G2 & $5(4.2)$ & $0(0)$ & $1(4.3)$ & $1(5.9)$ & \\
\hline & G3 & $110(93.2)$ & $14(93.3)$ & $22(95.7)$ & $16(94.1)$ & \\
\hline \multicolumn{2}{|l|}{ Presence of CIS } & $30(24.8)$ & $6(40)$ & $6(25)$ & $6(35.3)$ & 0.528 \\
\hline \multirow{4}{*}{$\begin{array}{l}\text { T-stage at the RC final } \\
\text { pathology }\end{array}$} & $\leq \mathrm{T} 1$ & $30(25.4)$ & $2(13.3)$ & $1(4.2)$ & $0(0)$ & \multirow{4}{*}{$<0.001$} \\
\hline & $\mathrm{T} 2$ & $63(53.4)$ & $5(33.3)$ & $10(41.7)$ & $0(0)$ & \\
\hline & T3 & $14(11.9)$ & $4(26.7)$ & $9(37.5)$ & $6(35.3)$ & \\
\hline & T4 & $11(9.3)$ & $4(26.7)$ & $4(16.7)$ & $11(64.7)$ & \\
\hline \multicolumn{2}{|c|}{ Number of dissected lymph nodes } & $12 \pm 5.7(1-30)$ & $11.7 \pm 4.1(7-24)$ & $13.4 \pm 6.2(4-33)$ & $14.1 \pm 4.2(8-21)$ & 0.333 \\
\hline \multicolumn{2}{|l|}{ Upstaging } & $31(25.8)$ & $9(60)$ & $9(90)$ & $17(100)$ & $<0.001$ \\
\hline \multicolumn{2}{|l|}{ SM positivity } & $9(7.4)$ & $4(26.7)$ & $5(20.8)$ & $7(41.2)$ & 0.001 \\
\hline \multicolumn{2}{|l|}{ ACT } & $25(20.7)$ & $5(33.3)$ & $13(54.2)$ & $6(35.3)$ & 0.01 \\
\hline \multicolumn{2}{|l|}{ Overall mortality } & $46(38)$ & $12(85.7)$ & $14(58.3)$ & $9(69.2)$ & 0.001 \\
\hline \multicolumn{2}{|l|}{ Overall survival } & $66 \pm 4.9(56.4-75.6)$ & $15.3 \pm 2.9(9.7-20.9)$ & $43.9 \pm 10.6(23.2-64.6)$ & $21.5 \pm 7.2(7.5-35.6)$ & $<0.001$ \\
\hline \multicolumn{2}{|l|}{ Cancer-specific mortality } & $31(25.6)$ & $8(57.1)$ & $11(50)$ & $8(61.5)$ & 0.003 \\
\hline \multicolumn{2}{|l|}{ Cancer-specific survival } & $77.8 \pm 5(68-87.6)$ & $21.2 \pm 4.6(12.1-30.2)$ & $54.8 \pm 12.2(30.7-78.8)$ & $24.5 \pm 8.1(8.6-40.4)$ & $<0.001$ \\
\hline
\end{tabular}

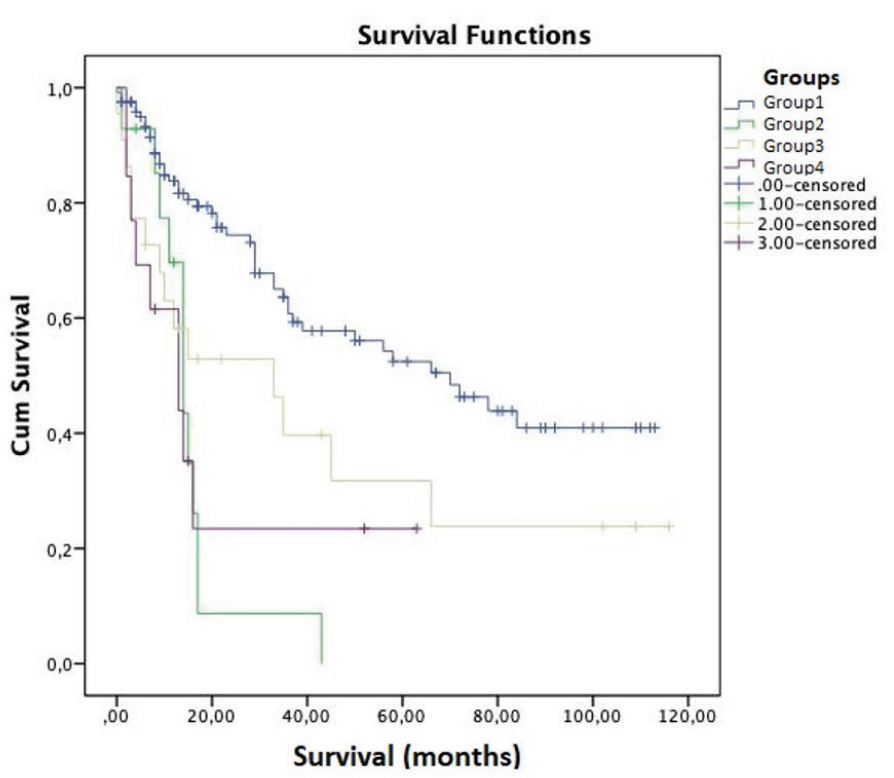

Figure 1. Overall survival curves of the groups based on LN and LVI status LN: Lymph node, LVI: Lymphovascular invasion

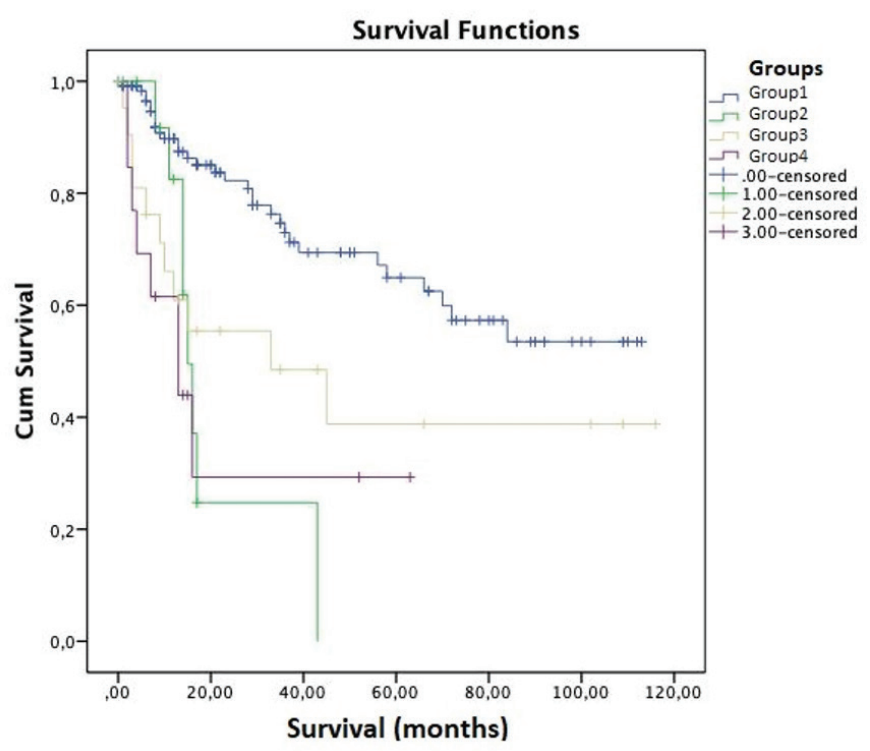

Figure 2. Cancer-specific survival curves of the groups based on LN and LVI status

LN: Lymph node, LVI: Lymphovascular invasion 
only. Another study conducted by Lotan et al. (22) revealed that LVI is also an important risk factor for local recurrence, distant metastasis, and overall disease recurrence in LN (-) patients only. LVI was observed to have a negative effect on OS and CSS in LN (-) patients (16). When we evaluated the OS and CSS data of group 1 [LVI (-); 66 and 77.8 months, respectively] and group 2 (LVI (+); 15.3 and 21.2 months, respectively), survival was favored in LVI (-) patients, in accordance with the literature. These data reveal that the negative effect of LVI on survival is more important in LN (-) patients than in LN (+) ones. Therefore, these patients should be followed up regularly. Despite the limited number of patients included in this research, complete data and detailed examinations of the four groups reduced the possibility of bias. Thus, the oncological results determined in this work are similar to those reported in previous studies. This similarity and additional findings highlight the importance of our study.

\section{Study Limitations}

The small number of patients and the weak distribution among the groups are important limitations in our study.

\section{Conclusion}

LVI was observed to be an independent prognostic factor affecting OS and CSS. ACT, especially in group 3, improved CSS, but SM positivity had a negative effect on survival rates. Although LVI is an important factor for predicting survival, especially in LN (-) patients, large-series studies are needed to investigate the importance of LVI in LN (+) patients and clarify its relationship with $L N$ positivity.

\section{Acknowledgements}

Publication: This study was presented in the $14^{\text {th }}$ International Urooncology Congress on December 6-10 in 2019, Antalya, Turkey.

Contribution: There is not any contributors who may not be listed as authors.

Conflict of Interest: No conflict of interest was declared by the authors.

Financial Disclosure: The authors declared that this study received no financial support.

\section{Ethics}

Ethics Committee Approval: This study is a retrospective cohort study.

Informed Consent: Retrospective study.

Peer-review: Externally and internally peer-reviewed.

\section{Authorship Contributions}

Concept: G.C., S.Ç., İ.B., Design: G.C., S.Ç., E.Ş., Data Collection or Processing: A.Y., Analysis or Interpretation: S.Ç., İ.H.B., T.D., Literature Search: G.C., S.Ç., B.G., Writing: G.C., S.Ç., S.Y.

\section{References}

1. Fang W, Yang Z, Chen T, et al. Ethnicity and survival in bladder cancer: a population-based study based on the SEER database. J Transl Med 2020;18:145.
2. Burger M, Catto JW, Dalbagni G, et al. Epidemiology and risk factors of urothelial bladder cancer. Eur Urol 2013;63:234-241.

3. Reuter EV, Melamed RM, The Urothelial Tract: Renal Pelvis, Ureter, Urinary Bladder and Urethra. In: Sternberg SS, ed. Diagnostic Surgical Pathology. Volume 2. 3rd ed. Philadelphia: Lipincott Williams \&Walkins; 1999. p. 1853-1891.

4. Albano JD, Ward E, Jemal A, et al. Cancermortality in the United States by education level and race. I Natl Cancer Inst 2007;99:1384-1394.

5. Hidas $G$, Pode $D$, Shapiro $A$, et al. The natural history of secondary muscle-invasive bladder cancer. BMC Urol 2013;13:23.

6. Alfred Witjes J, Lebret T, Comperat EM, et al. Updated 2016 EAU guidelines on muscle-invasive and metastatic bladder cancer. Eur Urol 2017;71:462-475.

7. Shariat SF, Karakiewicz PI, Palapattu GS, et al. Outcomes of radical cystectomy for transitional cell carcinoma of the bladder: a contemporary series from the bladder cancer research consortium. J Urol 2006;176:2414-2422.

8. Canter D, Guzzo TJ, Resnick MJ, et al. A thorough pelvic lymphnode dissection in presence of positive margins associated with better clinical outcomes in radical cystectomy patients. Urology 2009;74:161-165.

9. Sharma P, Zargar-Shoshtari K, Poch MA, et al. Surgical control and margin status after robotic and open cystectomy in high-risk cases: caution or equivalence? World J Urol 2017;35:657-663.

10. Yafi FA, Aprikian AG, Chin JL, et al. Impact of concomitant carcinoma in situ on Upstaging and out come following radical cystectomy for bladder cancer. World J Urol 2014;32:1295-1301.

11. Manoharan M, Katkoori D, Kishore TA, et al. Lymphovascular invasion in radical cystectomy specimen: is it an independent prognostic factor in patients without lymphnode metastases? World J Urol 2010;28:233-237.

12. Kanatani A, Nakagawa T, Kawai T, et al. Adjuvant chemotherapy is possibly beneficial for locally advanced or node-positive bladder cancer. Clin Genitourin Cancer 2015;13:107-112.

13. Mathieu R, Lucca I, Roupret M, et al. The prognostic role of lymphovascular invasion in urothelial carcinoma of the bladder. Nat Rev Urol 2016;13:471-479.

14. Albers P, Siener R, Kliesch S, et al. Risk factors for relapse in clinical stage I nonseminomatous testicular germ cell tumors: results of the GermanTesticular Cancer Study Group Trial. J Clin Oncol 2003;21:1505-1512.

15. Mari A, Kimura S, Foerster B, et al. A systematic review and metaanalysis of lymphovascular invasion in patients treated with radical cystectomy for bladder cancer. Urol Oncol 2018;36:293-305.

16. Bolenz C, Herrmann E, Bastian PJ, et al. Lymphovascular invasion is an independent predictor of oncological outcomes in patients with lymphnode negative urothelial bladder cancer treated by radical cystectomy: a multicentre validation trial. BJU Int 2010;106:493-499.

17. Shariat SF, Svatek RS, Tilki D, et al. International validation of the prognostic value of lymphovascular invasion inpatients treated with radical cystectomy. BJU Int 2010;105:1402-1412.

18. von Rundstedt FC, Mata DA, Groshen S, et al. Significance of lymphovascular invasion in organ-confined, node-negative urothelial cancer of the bladder: data from the prospective p53-MVAC trial. BJU Int 2015; 116:44-49.

19. Dohn LH, Illemann M, Høyer-Hansen G, et al. Urokinase-type plasminogen activator receptor (UPAR) expression is associatedwith T-stage and survival in urothelial carcinoma of the bladder. Urol Oncol 2015;33:165.e15-24. doi: 10.1016/j.urolonc.2014.12.001.

20. Moschini M, Shariat SF, Abufaraj M, et al. The presence of carcinoma in situ at radical cystectomy increases the risk of urothelial recurrence: implications for follow-upschemes. Urol Oncol 2017;35:151.e17151.e23. doi: 10.1016/j.urolonc.2016.11.003. 
21. Tilki D, Shariat SF, Lotan Y, et al. Lymphovascular invasion is independently associated with bladder cancer recurrence and survival in patients with final stage T1 disease and negative lymphnodes after radical cystectomy. BJU Int 2013;111:1215-1221.
22. Lotan Y, Gupta A, Shariat SF, et al. Lymphovascular invasion is independently associated with overall survival, cause-specific survival, and local and distant recurrence in patients with negative lymphnodes at radical cystectomy. J Clin Oncol 2005;23:6533-6539. 